\title{
Principles of Innovational Startup Selection for E-Platforms Placement
}

\section{Svetlana S. Morkovina}

Voronezh State Academy of Forestry and Technologies

\author{
Elena A. Kolesnichenko
}

Tambov State University name after G.R. Derzhavin

Valeriy A. Spesivtsev

Financial University under the Government of the Russian Federation (Lipetsk branch), Lipetsk, Russian Federation

Anna V. Ivanova

Voronezh State Academy of Forestry and Technologies

Doi:10.5901/mjss.2015.v6n6p201

Abstract

This article shows the research results of startup companies' selection for their further placement on E-platforms for the purpose of attracting investments. The brief analysis of innovation tendency for small enterprises is given in the article. The authors drew up a conclusion that the level of innovation projects realization is not currently reaching the potential possibility. It is related to a number of organizational factors. The authors determined that the key principles of the effective selection and placement of startup companies on E-platforms are the following: comprehension of evaluation (consideration of all the factors defining the investment attraction of startup company); adequate analysis (evaluation conformity of investment attraction of startup company with the features of an operating E-platform); compliance with needs (placement of the admitted startup company on the E-platform according to the category which is interesting for investor). Based on the expert analysis application, a number of factors determining the investment attraction of startup companies are singled out. The factors of regional level are as follows: existence of regional administration support of innovation projects, informational support of innovation activity, social and economic stability, and level of competition in the region. As for the level of industry sector: growth rate of potential of industry sector, efficiency of industry sector output, taxes and tax incentives, capital-intensiveness of output, and monopoly within the sector of industry. The key factors of the company are: efficiency of the resources used, organizational and juridical form of a startup company, marketing capabilities of innovation, technical and scientific potential of the company, financial conditions of the company. Detection methods for a startup company of high level of investment attraction are worked out. The given methods comprise a complex of analytical actions. They are: preparatory stage - selection of companies and innovation projects being expertized; main stage - fixing weighting coefficient for evaluation criteria applied for the level of investment attraction of a startup company; final stage - individual expert results processing.

Keywords: startup company, investment attractiveness of a startup company, E-platform, identification of investor. 


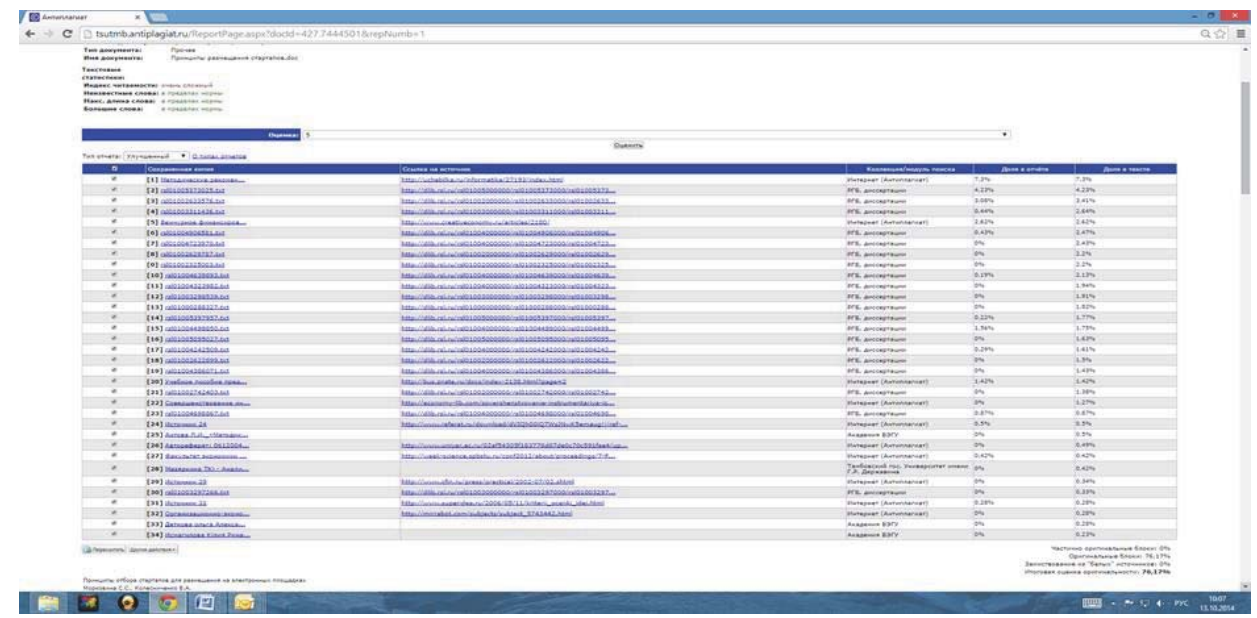

\section{Introduction}

The development of the industry of venture capital and direct investment in Russia is one of the top-priority directions of state innovation policy and a necessary condition of activation of innovation activities and upgrade of competitiveness of national economy. The low innovation activity in some branches of Russian economy is not connected with the absence of long-term ideas concerning investment. It is connected with the lack of development of infrastructure concerning the support of small innovational enterprises. The gap between Russia and the developed countries in the main indices of the development of small innovational enterprises remains significant. The proportion of small innovational enterprises in the total quantity of small enterprises of Russia is $0.8 \%$. The share of small innovation enterprises is about $0.3 \%$ of investments into the fixed capital and turnover and $0.6 \%$ of all people engaged in the sphere of small enterprise. As a comparison, the share of small innovational enterprises in the total quantity of small enterprises is: in France - 38\%, Great Britain - 24\%, Norway - 49\%, Germany - 62\%, and Ireland - 75\%.

It is impossible to overcome this lag without accelerated development of all the links of the infrastructure of small innovation enterprise support, including the institutions of investments and venture financing. However, in modern Russia it is very difficult to make innovatory business. Today it is unprofitable and extremely expensive activity. It is caused both by the disadvantages of subjective perception of Russian startup companies by the investors and the objective characteristics of the companies and projects. Russian investors don't want to invest their capital at the stage of idea or prototype. It is related to the fact that subjectively Russian investors are interested in supporting those companies that are looking for capital for the expansion of their existing business and not for the development of innovational ideas. In the established conditions, the process of "healthy selection" of innovational ideas and unpacked innovational projects is required. The majority of the projects at the early stage are unprofitable in the long-term perspective for the following reasons: there is no distinct business-plan, and substantiation of key characteristics is also missing; preliminary stage of the creation of startup companies is ineffectively supported by investors, because startupers' experience in the realization of innovatory projects and the development of innovatory ideas are not sufficient; the interaction between the investors and startupers is poorly organized; entrepreneurs and innovators don't have skills concerning the evaluation of their innovational potential and turning their innovations and ideas into a full-fledged market product.

The E-platform (electronic website) must become one of the tools for solving the problems mentioned above, as the instrument of information support for legal entities and individuals which implement entrepreneurial projects (startups) and investors. The scientific interpretation of the represented problems and the necessity for the development of principles of placing entrepreneurial projects (startups) have defined the actuality and practical significance of the research. This will provide investors with ample opportunities for the effective presentation of the companies, convenient and effective communications between all the categories of the market participants, and informative and analytical support of the companies. 


\section{Methods}

Investment attractiveness of a startup company can be defined by various sets of factors having the greatest significance in selection of one or another object of investment. Selection of factors for the analysis of one or another index is carried out on the basis of theoretical and practical knowledge, acquired in this branch. The value of complex classification of factors consists in the fact that it is possible to model financial and economic activities on the basis of this classification and carry out the complex search for inherent economic reserves, aimed to raise the efficiency of production.

All the factors, defining investment attractiveness, can be divided according to the source of their origin into internal and external ones. Internal factors depend on the activities of the economic entity (these are factors which can be influenced by the economic entities). Such factors consist of the system of organization management; nomenclature of the manufactured production; application of innovatory decisions in the technology of production and equipment. External factors are those factors which do not depend on the activity of the economic entity (economic peculiarities of the branch, the potential of the region in which the organization is functioning, legislation in the field of investment and so on).

In this article we'll proceed from the statement that it is expedient to define two environments in connection with innovatory activities of the enterprise: macroeconomic (external environment for an enterprise which will partially differ from the statements of economic theory) and microeconomic (internal environment for an enterprise which in turn should be differentiated to the level of the enterprise and to the level of innovation project). Consequently, the sum total of the determinants of innovational attractiveness of the project can be classified as the following (Figure 1).

The represented factors, as we believe, can have the most considerable influence on the investment attractiveness of innovational organizations. However, the analysis of all the totality of factors defining investment attractiveness of innovatory organizations is presumed to be rather difficult. This is why among the numerous varieties of expert methods it is advisable to use expert method of Delphy, in order to limit the quantity of factors to the most important ones.

Factors determining startup company's innovational attractiveness for investor

MACRO-LEVEL

Factors characterizing the national economy

- inflation expectations

- changes in the state economic policy

- changes in institutional environment

- changes in science and technology

- changes in political situation

Factors characterizing the sphere of activity

- constant business growth

- availability of analogues of the produced innovation in the market

MICRO-LEVEL

Factors characterizing an enterprise

- human factor (no lack in labor resources; good working team; experience in the innovation activity management; experience in scientific/technical and innovational activity)

- material resource supply (special equipment and machinery; own material resources; own technologies)

- financial factor (financial state of the innovational enterprise)

Innovational project factors

- technological factor (stage of realization of innovational product; opportunity to control the project; possibility to minimize risks)

- innovational factor (originality and significance of the project)

- consuming factor (having a consuming society; the analysis level of forecast according to market parameters; reasonability and demand of a project)

- project investment attractiveness

Work plan [Zakharova N. A., 2004]

1. It is necessary to determine a group of experts which define the influencing factors that influence and determine the investment attractiveness of enterprise. The experts' role (3 experts at least) is very important. They do not evaluate the factors in quality, but compare one factor to another. While comparing the factors, an expert determines the ratio between them in the "more", "less", and "equal" terms.

2. A special list showing the factor importance level is made for experts' evaluation of the factors. Comparing the factors (by pairs), an expert determines their influence on investment attractiveness of an organization. Results of experts' comparison are put in the table which has a form of a matrix. Based on the comparing 
results, the average comparing systems are built.

3. A square matrix of contiguity is formed to show the results of pair-wise experts' comparison of factors.

4. Relative weight of factors is calculated to show their importance level for investment attractiveness. It is done in several iterations. All the calculations are put into the table. As a result of the work of the expert team, enterprise managers, project managers, scientists, and marketing experts, 10 factors which determine the investment attractiveness of a startup company were selected. The results are shown in Table 1.

Table 1. Factors determining startup company investment attractiveness

\begin{tabular}{|c|c|}
\hline Level & Factors determining the investment attractiveness \\
\hline \multicolumn{2}{|l|}{ External } \\
\hline \multirow[t]{8}{*}{ Regional } & 1. State support in regional innovational sphere \\
\hline & 2. Regional support of innovational project and innovation leaders \\
\hline & 3. Capacity and paying capacity of home market \\
\hline & 4. Stable financial, credit, and banking system \\
\hline & 5. Informational support of innovational activity \\
\hline & 6. Soft loans and interest rates in credits \\
\hline & 7. Effective employment in innovation activity \\
\hline & $\begin{array}{l}\text { 8. Development of external economic connections in the innovational sphere } \\
\text { 9. Socio-economic stability and activation of entrepreneurship } \\
\text { 10. Level of competition in region }\end{array}$ \\
\hline $\begin{array}{l}\text { At the level of industries and activity fields } \\
\text { of a startup company }\end{array}$ & $\begin{array}{l}\text { 1. Capacity of industry sector market } \\
\text { 2. Growth rates of industry sector market potential } \\
\text { 3. Price flexibility } \\
\text { 4. Profitability of industry sector products } \\
\text { 5. Capital intensiveness of the industry sector } \\
\text { 6. Tax rates and tax incentives } \\
\text { 7. Development level of information infrastructure } \\
\text { 8. Technological advances in the industry sector } \\
\text { 9. Capital and science intensiveness of the products } \\
\text { 10. High economic risk }\end{array}$ \\
\hline \multicolumn{2}{|r|}{ (1) } \\
\hline At the level of startup companies & $\begin{array}{l}\text { 1. Type of ownership } \\
\text { 2. Organizational and juridical form of a startup company (physical entity, } \\
\text { entrepreneur without forming a legal entity, legal entity) } \\
\text { 3. Efficiency of the resources involved } \\
\text { 4. Number of performers and the level of labor motivation } \\
\text { 5. Innovation marketing } \\
\text { 6. Guaranteeing the rights of intellectual property protection } \\
\text { 7. Effective demand for innovational products } \\
\text { 8. Investors interested in a startup company } \\
\text { 9. Scientific and technological potential of a startup company } \\
\text { 10. Financial state of a startup company }\end{array}$ \\
\hline
\end{tabular}

It's necessary to study the impact of each factor on a startup company's investment attractiveness with the purpose of further research. The following data has been obtained as a result of the implementation of these methods (Table 2).

Table 2. Top-priority factors defining a startup company's investment attractiveness at different levels

\begin{tabular}{|l|c|}
\hline Name of a factor & Significance \\
\hline Factors defining the investment attractiveness of innovation organizations at the regional level \\
\hline 1. Government support for the region & 0.109 \\
\hline 2. Regional support for innovation projects & 0.125 \\
\hline 3. Informational support for innovations & 0.098 \\
\hline 4. Socio-economic stability and activation of entrepreneurship in the region & 0.125 \\
\hline 5. Level of competition in the region & 0.125 \\
\hline Factors defining the investment attractiveness at the industry sector level \\
\hline
\end{tabular}




\begin{tabular}{|l|c|}
\hline 1. Growth rates of an industry sector market potential & 0.147 \\
\hline 2. Profitability of industry sector products & 0.109 \\
\hline 3. Capital intensiveness of the industry & 0.112 \\
\hline 4. Tax rates and tax incentives & 0.109 \\
\hline 5. High economic risk & 0.118 \\
\hline Factors defining the investment attractiveness at the level of innovation organization \\
\hline 1. Efficiency of the resources used & 0.111 \\
\hline 2. Organizational and juridical form of a startup company & 0.123 \\
\hline 3. Innovation marketing & 0.112 \\
\hline 4. Financial state of a startup company & 0.111 \\
\hline 5. Scientific and technological potential of a startup company & 0.204 \\
\hline
\end{tabular}

In conclusion it's necessary to note that during the conducted research a number of factors, defining a startup company's investment attractiveness, have been studied. With the help of experts' questionnaire analysis, specific factors that determine a startup company's investment attractiveness and that will further be used to specify the evaluation method of a startup company have been discovered. These factors are:

- at the regional level: government support for the region, regional support for innovational projects, informational support for innovations, social and economic stability, level of competition in the region;

- $\quad$ at the industry sector level: growth rates of an industry sector market potential, profitability of industry sector products, tax rates and tax incentives, capital intensiveness and monopoly of industry sector;

- $\quad$ at the level of organization: efficiency of the resources involved, organizational and juridical form of a startup company, innovation marketing, scientific and technological potential of an enterprise, financial state of enterprise.

\section{Results of the Analysis}

In authors' opinion, in order to select startup companies for their placement on the electronic websites and to consider the possibilities of their further evaluation and maintenance, the following components are the most important [Kolesnichenko E.A. et al, 2014].

Originality of the project - a quality of a product that is unique, peculiar, and non-standard. This is the most common description to assess the product of intellectual creativity. The project is considered original if there are no similar ones that are already known.

Innovation of the project is one of the key characteristics of a startup company. Innovation appears in the field extension of the study of a problem. Unlike the originality, the principal innovation assumes the patent purity, license protection, priority of innovation areas, and competitiveness of the innovation introduced.

Development of the project is the intermediate characteristic that assumes the presence of basic components of development level (that could be increased) and the degree of complexity (assuming the consideration of the variety of factors - technological, economic, information, ecological, social and others).

Potential efficiency of the project implementation - a category reflecting the conformity of the project to the goals and interests of project participants. The efficiency of innovation project assumes the conformity of the obtained results, both economic (especially profit) and external economic (removal of social tension in the region), to the project costs.

The resource supply of the project - the presence and sufficiency of resources in the region for their prospective implementation introduced by the initiator of the project. Within the resource supply it's necessary to differentiate the specific conditions of the project realization and the resource supply.

Commercialization of the project - commercial potential and degree of readiness for the study. Evaluating the level of the project commercialization, an expert assesses, on what scale (country, region, enterprise) and in what economic sectors the project can be commercialized. The presence of commercial and budget efficiency is of particular importance.

In accordance with the assumed components, the criteria for evaluation of innovational potential of the enterprise (Table 2) and parameters, which are taken into account during calculation, have been determined (Table 3). 
Table 3 - Basic criteria and their contents

Name of criterion Influence of criterion Values of criterion

a) originality of the project

1 Scale of originality (global, sectorial, territorial, private level, scale is not defined)

2 Degree of originality (radical, combinatory modifying character, project is not original) Total (average) evaluation

b) novelty of the project:

3 Level of innovation confirmation (high, medium, low, no confirmation)

Total evaluation

c) elaboration of the project

4 Level of elaboration (full elaboration, sufficient, insufficient, project is not elaborated)

5 Level of complexity (high, medium, low, consideration of factors has not been done)

The total (average) evaluation

d) potential efficiency

6 Level of efficiency (high, medium, low, project is not effective)

Total evaluation

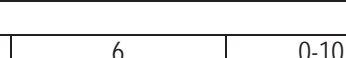

e) Resource supply of the project

7 level of requirement for special preparation (low, average, high, project is hard to evaluate)

8 level of resources supply (high, average, low, resources evaluation has not been conducted)

Average evaluation

e) commercialization of the project:

\begin{tabular}{|l|l|l|}
\hline 9 & $\begin{array}{l}\text { Scale of commercialization (fully commercialized, substantially commercialized, can be commercialized, project is } \\
\text { not commercialized) }\end{array}$ & $9-10$ \\
\hline Total evaluation & $0-10$ \\
\hline
\end{tabular}

Table 3 - Markers and parameters taken into account

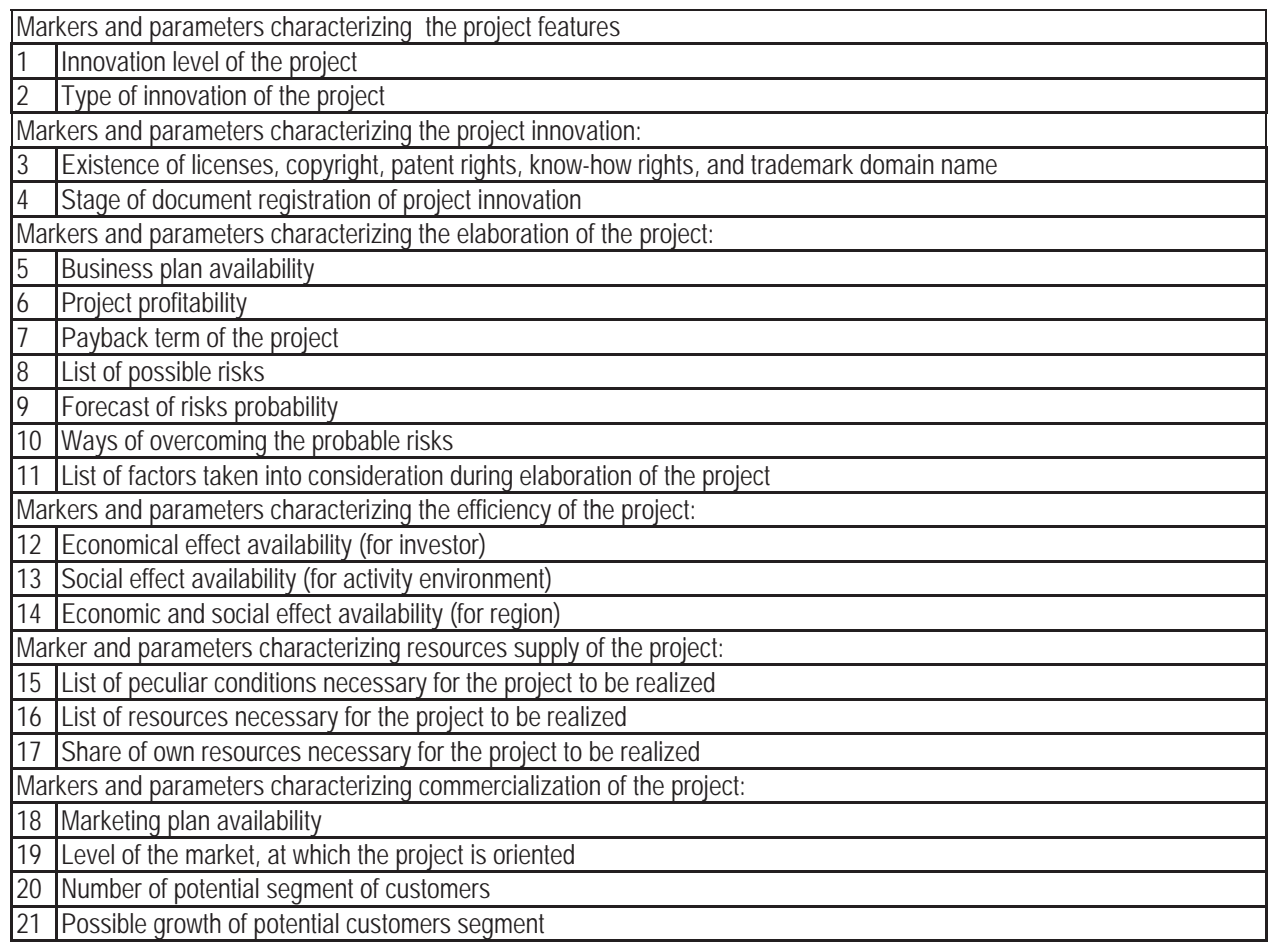


Thus, analysis and evaluation of investment attraction level of startup companies are realized with an expert method in three stages:

- $\quad$ preparatory stage - enterprises and innovational projects are selected for the expertise to be done, agreement conclusion for expertise to be done, formation of expert groups (the experts include the leading specialists in the field of economics, science and engineering, and marketing with the experience of work in certain industry segment no less than 15 years. A number of members of expert group depends on a certain startup company and should comprise 6 to 18 members), their instruction, enterprises' preparation of primary informational materials, duration - 1.5-2 months;

- main stage - identification of weighing coefficients for the evaluation criteria of startup company investment attractiveness (to check the expert evaluation marks of the investment attractiveness of the startup company, the standard method is applied. Every criteria is given a certain range of numbers within the interval 0-10: "excellent" evaluation mark corresponds to a number within the interval from 8.09 to 10.00; "average" evaluation mark corresponds to a number within the interval 5.09-8.0; "low" evaluation mark corresponds to a number in the interval 2.09-5.0); "bad" evaluation mark corresponds to a number less than 2.0), individual activity of experts with the informational maps of the enterprises and preparation of expert reports, duration - 1 month;

- final stage - processing of individual expert conclusions, consideration of the marks received at the mutual meeting of the department for preliminary expertise of electronic Website (taking in account the determined ratio between quantity and quality index of private criteria, you can find the investment attractiveness level of a startup company to be "high" with index 8-10; "middle" with index 5-8 and "low" with index 2-5; a project is unattractive for investment with index 2 or less - then startup company company's managers, final results, and expert recommendations, as well as the received evaluation results are given to experts for revising, their opinions are generalized in the electronic website preliminary testing department and are used to prepare a report on the work done. A report can be different: a project is accepted without correcting; a project is accepted after some notes have been corrected; a project is accepted after correcting gross mistakes; a project is not accepted), duration -1 month.

\section{Discussion}

It is necessary to stress the idea that a lot of scientific works describe investment attractiveness factors and their evaluation methods. Majority of these works are based upon the famous index NPV evaluation method in a traditional form [Korenyako A. A., 2011].

Today, special literature on Economics recommends assessing the effectiveness of innovative projects using the special effectiveness scale and their selection for financial support.

In the text, there are no special features on the instructions usage to evaluate innovative projects. Calculation method Ave Maria, as well as scoring method, are the best ones to find a startup company with a high investment attractiveness level but for their lack of evaluation characteristics; nevertheless, they are very good to compare different projects when choosing the best investment way. Berkus method is the best one from adapting point of view to be included into the electronic website, but as for criteria set it must be corrected to be more objective.

On the whole, one may think that enterprise investment attractiveness is determined by its managerial system, staff, paying capacity state, and market activity. According to this point of view, the following aspects are to be evaluated:

- managerial system; - staff; - economic, scientific and technical base; market activity; - results of current financial and economic activities.

This task is to create methods for complex evaluation of startup company investment attractiveness together with the key factors; so, selecting parts in a startup company structure which are the most influencing innovation and investment characteristics. After that evaluation criteria of their state, as well as investment attractiveness, should be determined.

\section{Conclusion}

The research process proved the investment attractiveness to be related to the investment objects: country, region, organization, or certain startup company. There are specific factors for startup company and they determine investment attractiveness; these investment attractiveness factors are found with the help of experimental methods and their importance level is determined by calculation. 
The main factors to determine the investment attractiveness of a startup company in a region - according to the research work - are as follows: - state support for a region; - regional support for innovational projects; - informational support for innovational activity; - social and economic stability; - competition level in a region; in the industry sector: certain market potential growth; - profitability of the industry sector production; - tax preferences; - financial capacity and monopoly in the industry sector or organization; - efficiency of the resources used; - organizational and juridical form of a startup company; marketing of innovation; - scientific and technical potential of organization; - financial state of organization.

The discussed investment attractiveness methods of projects should be used when evaluating a startup company, because they are devoted to profitability evaluation project; this is the key moment when an investor, not the experts, makes the investment decision about accepting a startup company to the electronic website.

The analysis of a startup company methods used resulted in the necessity to create a criteria group to be a backbone for making the decision about a project's acceptance into a database. The criteria to find startup companies with high level of investment attractiveness for their further acceptance to the electronic website are suggested: originality of a project (originality level and scale); innovation of a project (level of innovation confirmation); project elaboration (elaboration level; complexity level); future efficiency (efficiency level); resource supply of a project (level of need for special preparation; level of resource supply); commercialization of the project (commercialization scale).

Analysis and evaluation of the investment attractiveness of startup companies are being carried out by the method of expertise and passed three stages: preliminary stage (selection of enterprises and innovation projects for expertise, formation of expert groups, their instruction, preparation of the initial informative materials); main stage (establishment of weight coefficients for the used criteria of the investment attractiveness level evaluation of startup companies, preparation of expert conclusions); final stage (processing of individual expert conclusions, discussion of estimations received, approval of the conclusions and recommendations of experts).

\section{Acknowledgements}

The article is prepared in the course of the first stage of scientific research work on the topic: "Analysis of the condition of infrastructure, providing interaction between investors and startup companies", included into state contract No. 11 dated July 25, 2014, concluded between the department of economic development of the Voronezh Oblast (Voronezh) and FSBEI HPE "VSAFT" (Federal State Budget Educational Institution of Higher Professional Education "Voronezh State Academy of Forestry and Technologies").

\section{References}

Babushkin V.A. Organization and Methods of Investment Attractiveness Analysis of the Economic Entity / Theses of candidate of economic sciences. Voronezh, 2009. $180 \mathrm{p}$.

Goncharova O.U. Venture Financing of Small Innovation Entrepreneurship in Russia: Problems and Perspectives // Creative economy. \# 2 (26). 2009. P. 103-107.

Zakharova N.A. Investment Attractiveness of the Agricultural Enterprise / Theses of candidate of economic sciences. Voronezh, 2004. $179 \mathrm{p}$.

Kolesnichenko E.A. Methodological Instruments of the Investment Attractiveness Level Evaluation of Startup Companies.

Kolesnichenko E.A., Savinova O.V. Cluster Approach as the Instrument of the Creation of Favorable Investment and Business Climate in the System of Guaranteeing the Competitiveness of the Territory // Social and economic phenomena and processes. \#2. 2014. P. $47-55$.

Koreniako A.A. The Improvement of Instruments of the Economic Effectiveness Research in the Introduction of Innovatory Technological Equipment / Theses of candidate of economic sciences. Tambov, 2011. 155 p.

Steve Blanc, Bob Dorf. The Startup Owner's Manual. M.: Alpina Publisher, 2014. 616 p. ISBN 978-5-9614-4538-1.

Usenko A.M. The Financial Provision of Innovatory Active Small Firms / thesis of candidate of economic sciences. Rostov-on-Don, 2010. $174 \mathrm{p}$.

Shutilina E.U. Forming of innovation politics of enterprises (on the example of the enterprises of industry) / thesis of candidate of economic sciences. Voronezh, 2010. $184 \mathrm{p}$.

Eric Reese. The Lean Startup: How Today's Entrepreneurs Use Continuous Innovation to Create Radically Successful Business. M.: Alpina Publisher, 2014. 256 p. ISBN 978-5-9614-4628-9. 